\title{
Effects of alloying elements on defect structures in the incubation period for void swelling in austenitic stainless steels
}

\section{AUTHOR(S):}

Horiki, M.; Yoshiie, T.; Huang, S.S.; Sato, K.; Cao, X.Z.; Xu, Q.; Troev, T.D.

\section{CITATION:}

Horiki, M.... [et al]. Effects of alloying elements on defect structures in the incubation period for void swelling in austenitic stainless steels. Journal of Nuclear Materials 2013, 442(1-3, Supplement 1): S813-S816

\section{ISSUE DATE:}

2013-11

URL:

http://hdl.handle.net/2433/179300

\section{RIGHT:}

(C) 2013 Elsevier B.V.; This is not the published version. Please cite only the published version.; この論文は出版社版でありません。引用の際に は出版社版をご確認ご利用ください。 


\title{
EFFECTS OF ALLOYING ELEMENTS ON DEFECT STRUCTURES IN THE INCUBATION PERIOD FOR VOID SWELLING IN AUSTENITIC STAINLESS STEELS
}

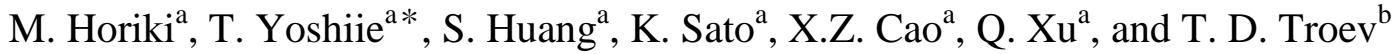 \\ ${ }^{a}$ Research Reactor Institute, Kyoto University, Osaka, Japan \\ ${ }^{b}$ Institute for Nuclear Research and Nuclear energy, Bulgarian Academy of Sciences, \\ Tzarigradsko, Chaussee, Sofia 1784, Bulgaria
}

Positron lifetime measurements were used to study the effects of alloying elements on the defect structure during the incubation period for void swelling in several fcc model alloys. Pure $\mathrm{Ni}$, four model alloys (Fe-Cr-Ni, Fe-Cr-Ni-Mo-Mn, Fe-Cr-Ni-Mo-Mn-Si and Fe-Cr-Ni-Mo-Mn-Si-Ti), and four commercial alloys (SUS316LSS, SUS316SS, SUS304SS and Ti added modified SUS316SS) were irradiated with electrons and neutrons. Even at 363 and $573 \mathrm{~K}$ to a dose of 0.2 $\mathrm{dpa}$, an effect of alloying elements was observed. At $363 \mathrm{~K}$ irradiation, voids were formed only in $\mathrm{Ni}$ and $\mathrm{Fe}-\mathrm{Cr}-\mathrm{Ni}$. At $573 \mathrm{~K}$ irradiation, voids were formed in $\mathrm{Ni}$ and all model alloys, though the concentration depended on the alloying elements. In commercial alloys, precipitates were formed instead of vacancy clusters, which prevented void growth.

Corresponding author: Toshimasa Yoshiie

Research Reactor Institute, Kyoto University, Kumatori, Sennan, Osaka 590-0494, Japan

yoshiie@ @ri.kyoto-u.ac.jp

Tel: +81-72-451-2473

Fax: $+81-72-451-2658$ 


\section{Introduction}

A transient stage or incubation period before steady void swelling under neutron irradiation exists in most nuclear materials. This period is important because it determines the duration of service in nuclear systems. Though several theoretical analyses of the period exist (recent examples [1,2]), few experimental studies have been performed for the detection of vacancies and their clusters. This is because most of these studies used transmission electron microscopy (TEM), however point defects and their small clusters are below TEM resolution limits and therefore impossible to detect.

Positron annihilation spectroscopy can be used to detect small vacant sites, which are below the resolution limit of TEM. The authors studied defect structures during the incubation period after electron and neutron irradiations using positron annihilation lifetime measurements in austenitic stainless steels [3, 4]. There have been many studies of the effect of alloying elements on void growth and swelling in austenitic stainless steels. A lengthy discussion of this topic is in a book [5]. However, studies were mainly high dose irradiation and did not discuss defect structures during the incubation period. In our previous experiments following electron irradiation of $4 \times 10^{-3}$ dpa at $100 \mathrm{~K}$, measurements taken at room temperature found that mainly single vacancies existed in commercial alloys and in model alloys. At the higher temperature of $563 \mathrm{~K}$, the lifetimes of precipitates and/or large stacking fault tetrahedra were detected in Ti-added modified SUS316SS after neutron irradiation below $0.02 \mathrm{dpa}$. After increasing the dose to $5 \mathrm{dpa}$, voids were detected.

To clarify the effect of alloying elements on the incubation period, this study investigated defect structures after electron irradiation and fission neutron irradiation using positron annihilation lifetime measurements.

\section{Experimental procedures}

The specimens used in this study were $99.99 \%$ pure $\mathrm{Ni}$, four model alloys, and four commercial alloys, as listed in Table 1 . In the four model alloys, no carbides were formed by heat treatment because of low carbon concentration. All specimens were fabricated as disks, 0.1 $\mathrm{mm}$ thick and $3 \mathrm{~mm}$ in diameter, which were annealed at $1323 \mathrm{~K}$ for $1 \mathrm{~h}$ in a vacuum of $10^{-4} \mathrm{~Pa}$ and cooled to room temperature. The cooling rate was sufficiently high and no precipitates were observed via TEM, even in commercial alloys. Electron irradiations were performed using an electron linac at the Research Reactor Institute, Kyoto University with an accelerating voltage of $30 \mathrm{MeV}$ at $343 \mathrm{~K}\left(1.2 \times 10^{-2} \mathrm{dpa}, 8 \times 10^{-8} \mathrm{dpa} / \mathrm{s}\right)$ and at $573 \mathrm{~K}\left(1.5 \times 10^{-2} \mathrm{dpa}, 8 \times 10^{-8} \mathrm{dpa} / \mathrm{s}\right)$. Fission neutron irradiations were performed using the Kyoto University Reactor at $573 \mathrm{~K}$ to a dose of $1.6 \times 10^{-3} \mathrm{dpa}\left(4 \times 10^{-9} \mathrm{dpa} / \mathrm{s}\right)$ and BR-2 of SCK $\cdot \mathrm{CEN}$ at 363 and $573 \mathrm{~K}$ to a dose of about $0.2 \mathrm{dpa}$ $\left(1 \times 10^{-7} \mathrm{dpa} / \mathrm{s}\right)$. After the introduction of defects by irradiation, positron annihilation lifetimes of the specimens were measured at room temperature using a conventional fast-fast spectrometer with a time resolution of $190 \mathrm{ps}$ (full width at half maximum), and each spectrum was accumulated to a total of $1 \times 10^{6}$ counts. The positron lifetime spectra were analyzed using the PALSfit program [6] and, if possible, the lifetimes were decomposed into two or three components. Otherwise, only a mean lifetime was obtained.

The positron annihilation lifetime of $\mathrm{Fe}-14 \mathrm{Cr}-13 \mathrm{Ni}$, a model alloy of austenitic stainless steel, was calculated based on first principles, using the Monte-Carlo density-functional theory and a local-density approximation [7]. The lifetimes were 106 and 183 ps for positrons annihilated in the matrix and in a single vacancy, respectively [4]. These values were almost the same as those of $\mathrm{Ni}[8,9]$ and the lifetime of $\mathrm{Ni}$ was used for the identification and estimation of the size of defect clusters (e.g., voids and stacking fault tetrahedra) in austenitic stainless steels. The estimated lifetimes are in Table 2.

\section{Results}




\subsection{Electron irradiation}

Before irradiation, the positron annihilation lifetimes of all specimens were not decomposed into two or three components and only mean lifetimes, between 106 to 109 ps, were obtained. These values indicate that positrons were annihilated in the matrix. The results of electron irradiation at $343 \mathrm{~K}$ to a dose of $1.2 \times 10^{-2} \mathrm{dpa}$ are shown in Fig. 1. The long lifetime of positron annihilation depends on the size of the vacant site where the positrons were annihilated. The lifetimes which were longer and shorter than that of single vacancies (176 ps) suggest the existence of larger vacancy clusters (voids) and smaller spaces than single vacancies, respectively. The high intensity of long lifetime indicates a high concentration of annihilation sites. No differences were observed between specimens except Ni. Clusters of three vacancies were detected in $\mathrm{Ni}$, while only single vacancies were found in the other alloys. Fig. 2 shows the results of $573 \mathrm{~K}$ electron irradiation to a dose of $1.5 \times 10^{-2} \mathrm{dpa}$. There were large differences between $\mathrm{Ni}$ and the model alloys, and the commercial alloys. $\mathrm{Ni}$ and the model alloys were decomposed into two components. The mean lifetime of the irradiated commercial alloys was almost the same as that of the unirradiated ones.

\subsection{Neutron irradiation}

Neutron irradiation was performed at $363 \mathrm{~K}$ to a dose of $0.2 \mathrm{dpa}$. After irradiation, the lifetimes changed (Fig. 3). Large voids were formed in $\mathrm{Ni}$ and the ternary model alloy (A), and single vacancies were formed in the other alloys.

At the high temperature irradiation of $573 \mathrm{~K}$ at $1.6 \times 10^{-3} \mathrm{dpa}$, the mean lifetimes were lower than those at the low temperature (Fig. 4). The lifetime $\tau_{2}$ of $\mathrm{Ni},(\mathrm{A})$ and (B), indicated the formation of voids. In commercial alloys, a lifetime of 130-140 ps was obtained, indicating that voids were not formed, but other defects were formed.

The mean lifetimes of neutron-irradiated specimens at $1.6 \times 10^{-3} \mathrm{dpa}$ (Fig. 4) was higher than those of electron irradiated ones at $1.5 \times 10^{-2}$ dpa (Fig. 2). This was caused by the effect of cascade formation under neutron irradiation. In each cascade, a high density of vacancies is formed, which promotes easy cluster formation. By increasing the irradiation dose to 0.2 dpa, the mean lifetimes increased in all specimens (Fig. 5), and the three-component analysis was possible. In $\mathrm{Ni}$ and the four model alloys, voids were formed as shown in $\tau_{3}$. Lifetimes of about $150 \mathrm{ps}$ were obtained as the mean lifetimes in commercial alloys. The lifetimes corresponded to those of stacking fault tetrahedra [8] and grain boundaries of precipitates.

\section{Discussion}

The effect of alloying elements was detected on void formation. Under electron irradiation at a temperature of $343 \mathrm{~K}$, vacancy clusters formed only in Ni. Under neutron irradiation at a temperature of $363 \mathrm{~K}$, large voids formed in $\mathrm{Ni}$ and (A), but only single vacancies formed in the other alloys. Although voids formed in $\mathrm{Ni}$ and $(\mathrm{A})$, the intensities $l_{2}$, which present the ratio of positrons annihilated at voids, indicated that the number of voids in (A) was very small compared to $\mathrm{Ni}$. These are effects of $\mathrm{Cr}$ which is an oversized atom in Fe-Cr-Ni alloys [10]. Oversized atoms interact with vacancies. The trapping of point defects reduces the nucleation and growth of voids [11]. Under neutron irradiation at a temperature of 573 to a dose of $1.6 \times 10^{-3}$ dpa, voids were formed in $\mathrm{Ni},(\mathrm{A})$ and (B). With an increased dose of $0.2 \mathrm{dpa}$, voids were formed even in (C) and (D), though the number of voids was small. These results indicate that the addition of $\mathrm{Si}$ and $\mathrm{Ti}$ prevented void formation. The influence of undersized atom $\mathrm{Si}$ in austenitic stainless steels on swelling occurs by many mechanisms [12]. By interacting with point defects, $\mathrm{Si}$ is known to change the mobility of both interstitials and vacancies. Precipitates of $\mathrm{TiC}$ formed during irradiation are neutral sinks for vacancies and interstitials and induce recombination between vacancies and interstitials [13]. But in (D), the C concentration was less 
than $0.002 \%$ and the formation of $\mathrm{TiC}$ was not significant. It is concluded that $\mathrm{Ti}$ in austenitic stainless steels reduces the free vacancy concentration due to vacancy trapping by $\mathrm{Ti}$ which is oversized atom, and reduced the swelling [14, 15].

The lifetime of 140 - $150 \mathrm{ps}$ in commercial alloys corresponded to that of precipitates and stacking fault tetrahedra. In these four alloys, the formation of stacking fault tetrahedra was expected to be the same as in the model alloys. One difference between model alloys and commercial alloys is the existence of $\mathrm{C}$ in commercial alloys. Even SUS316L contained C. Metal carbides commonly formed by the irradiation of austenitic stainless steels have incoherent grain boundaries with the matrix, therefore vacant spaces smaller than single vacancies are formed. For the formation of metal carbides, the migration of interstitial $\mathrm{C}$ is important as well as the accumulation of carbide-former elements such as $\mathrm{Cr}$, Mo and Ti by vacancies. The $\mathrm{C}$ migration is promoted by the formation of self-interstitials during irradiation. TEM identified the formation of metal carbides in austenitic stainless steels at higher temperatures and higher irradiation doses than the present experiment [4]. However, a strong possibility exists for the formation of very small precipitates at low temperatures and low doses, which are detected by positron annihilation lifetime measurements. The interface between the precipitates and matrix will act as a sink for both interstitials and vacancies, and prevent void growth. To finish the incubation period of void swelling, the coalescence of precipitates and/or purification of matrix will be required.

\section{Conclusion}

Positron annihilation lifetime measurements make it possible to detect defect clusters below the TEM resolution limit. Damaged structures in $\mathrm{Ni}$, commercial alloys of austenitic stainless steels, and their model alloys during the incubation period of void swelling were studied by electron irradiation and neutron irradiation. The effects of alloying elements, $\mathrm{Cr}, \mathrm{Si}$, Ti and $\mathrm{C}$ were detected even by low dose irradiation of $1.6 \times 10^{-3} \mathrm{dpa}$ and a low temperature of $343 \mathrm{~K}$. At a high temperature of $573 \mathrm{~K}$ to a dose of $0.2 \mathrm{dpa}$, voids were formed in $\mathrm{Ni}$ and model alloys, and precipitates were formed in commercial alloys. In this irradiation range, the formation of precipitates prevented void growth in the commercial alloys.

\section{Acknowledgments}

This study was performed under the sponsorship of JNES (Japan Nuclear Energy Safety Organization) open application research project for enhancing the basis of nuclear safety, with support from a Grant-in-Aid for Science Research (B) by JSPS (Task No. 22360401). A part of this study was a result of "Clarification of material behaviors in accelerator driven systems by an FFAG accelerator" carried out under the Strategic Promotion Program for Basic Nuclear Research by the Ministry of Education, Culture, Sports, Science and Technology of Japan.

\section{References}

[1] R.E. Stoller, S.I. Golubov, C. Domain, C.S. Becquart, J. Nucl. Mater. 382 (2008) 77.

[2] M. P. Surh, J. B. Sturgeon, W. G. Wolfer, J. Nucl. Mater. 378 (2008) 86.

[3] T. Yoshiie, X.Z. Cao, K. Sato, K. Miyawaki, Q. Xu, J. Nucl. Mater. 417 (2011) 968.

[4] T. Yoshiie, X.Z. Cao, Q. Xu, K. Sato, T. D. Troev, Phys. Status Solidi (c) 6 (2009) 2333.

[5] G. S. Was, Fundamentals of Radiation Materials Science, Springer, Berlin, New York, 2007, p405.

[6] P. Kirkegaard, J. V. Olsen, M. Eldrup, N. J. Pedersen, Ris $\varnothing$ DTU, February 2009, ISBN $978-$ 87-550-3691-8, p44, http://palsfit.dk/ .

[7] B .L. Shivachev, T.Troev, T.Yoshiie, J. Nucl. Mater. 306 (2002) 105.

[8] E. Kuramoto, T. Tsutsumi, K. Ueno, M. Ohmura, Y. Kamimura, Comp. Mater. Sci. 14 (1999) 28.

[9] H. Ohkubo, Z. Tang, Y. Nagai, M. Hasagawa, Y. Tawara, M. Kiritani, Mater. Sci. Eng. A 350 
(2003) 92.

[10] H. Kinoshita, S. Watanabe, S. Mochizuki, N. Sakaguchi and H. Takahashi, J. Nucl. Mater. 239 (1996) 205.

[11] L. K. Mansur, M. H. Yoo, J. Nucl. Mater. 74 (1978) 228.

[12] S.I. Porollo, S.V. Shulepin, Yu.V. Konobeev, F.A. Garner, J. Nucl. Mater. 378 (2008) 17.

[13] C. David, B.K. Panigrahi, S. Balaji, A.K. Balamurugan, K.G.M. Nair, G. Amarendra, C.S. Sundar, B. Raj. J. Nucl. Mater. (2008) 132.

[14] T. Kato, H. Takahashi , M. Izumiya, Mater. Trans., JIM 32 (1991) 921.

[15] A.Yabuuchi, M. Maekawa, A. Kawasuso, J. Nucl. Mater. 430 (2012) 190.

Table 1 Specimens and compositions.

\begin{tabular}{ll}
\hline \multicolumn{2}{l}{ Specimens } \\
\hline $\mathrm{Ni}$ & Pure Ni (99.99\%) \\
$\mathrm{A}$ & Fe-16.13Cr-16.96Ni \\
$\mathrm{B}$ & $\mathrm{Fe}-15.39 \mathrm{Cr}-15.92 \mathrm{Ni}-2.68 \mathrm{Mo}-1.89 \mathrm{Mn}$ \\
$\mathrm{C}$ & $\mathrm{Fe}-15.27 \mathrm{Cr}-15.8 \mathrm{Ni}-2.66 \mathrm{Mo}-1.88 \mathrm{Mn}-0.53 \mathrm{Si}$ \\
$\mathrm{D}$ & Fe-15.27Cr-15.8Ni-2.66Mo-1.88Mn-0.53Si-0.24Ti \\
$\mathrm{J}$ & Ti added modified SUS316SS \\
& Fe-15.27Cr-15.8Ni-2.66Mo-1.88Mn -0.53Si-0.24Ti-0.055C-0.024P \\
E & SUS316L SS Fe-17.35Cr-12.05N-2.08Mo-0.85Mn-0.47Si-0.019C-0.027P-0.001S \\
F & SUS316SS Fe-19.22Cr-12.58Ni-2.26Mo-1.82Mn-0.39Si-0.05C-0.019P-0.004S \\
G & SUS304 Fe-18.12Cr-9.08Ni-0.85Mn-0.48Si-0.05C-0.027P-0.002S \\
\hline
\end{tabular}

Table 2 Positron annihilation lifetimes in Ni [7,8]. V1 and Vn represent single vacancies and voids of $n$ vacancies, respectively. $\mathrm{Sm}$ is stacking fault tetrahedra of $\mathrm{m}$ vacancies.

\begin{tabular}{cccccccccccc}
\hline Size of V clusters & V1 & V2 & V5 & V13 & V19 & V43 & V79 & S3 & S10 & S21 & S28 \\
\hline Life time (ps) & 176 & 195 & $264-297$ & 341 & 371 & 410 & 427 & 183 & 170 & 155 & 130 \\
\hline
\end{tabular}



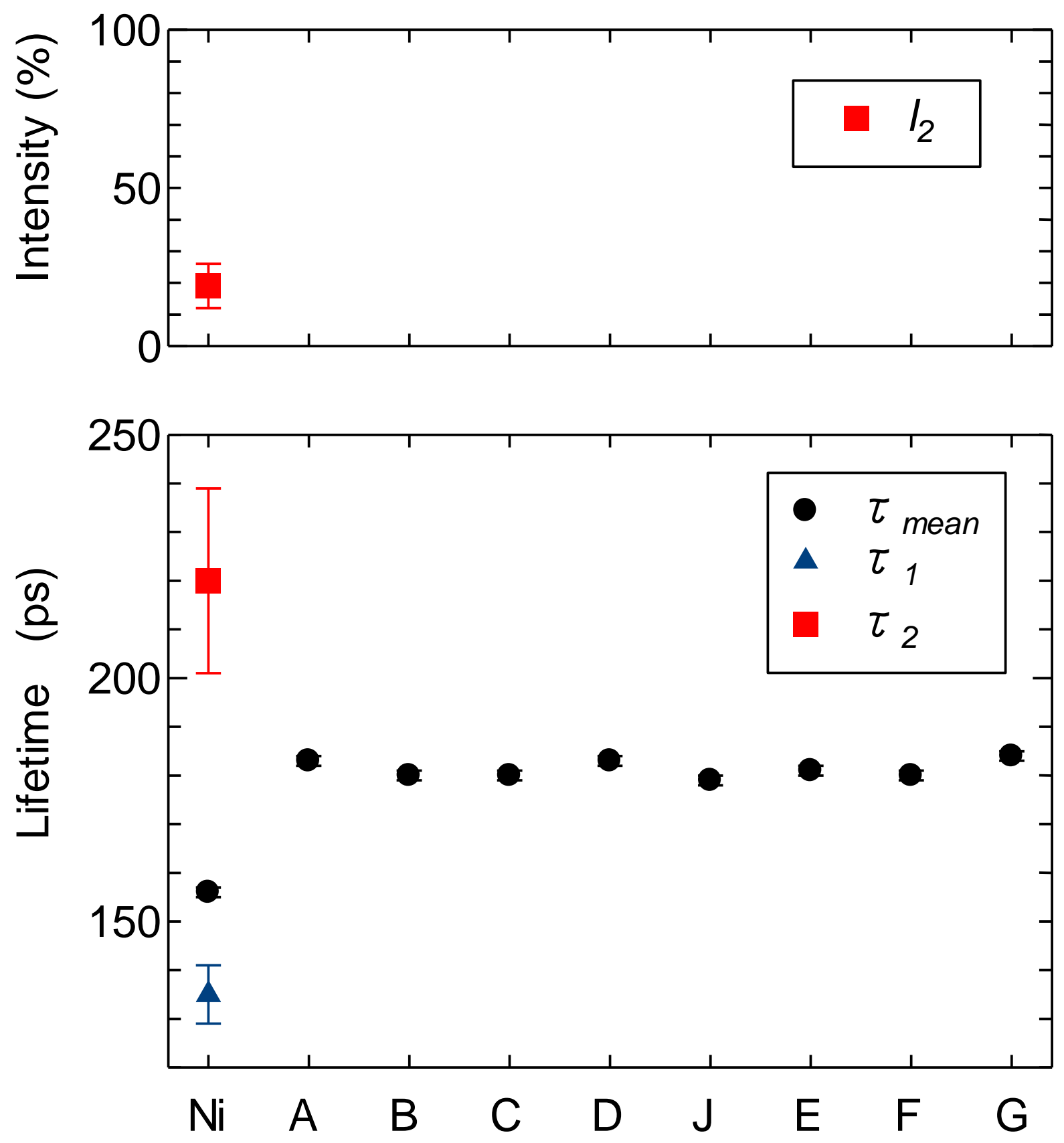

Figure 1 Positron annihilation lifetimes of electron irradiated $\mathrm{Ni}$, model alloy and austenitic stainless steels at $343 \mathrm{~K}$ to a dose of $1.2 \times 10^{-2}$ dpa. $\tau_{\text {mean }}$ is the mean lifetime, and $\tau_{1}, \tau_{2}$ and $I_{2}$ are the short lifetime, long lifetime and the intensity of the long lifetime, respectively. 

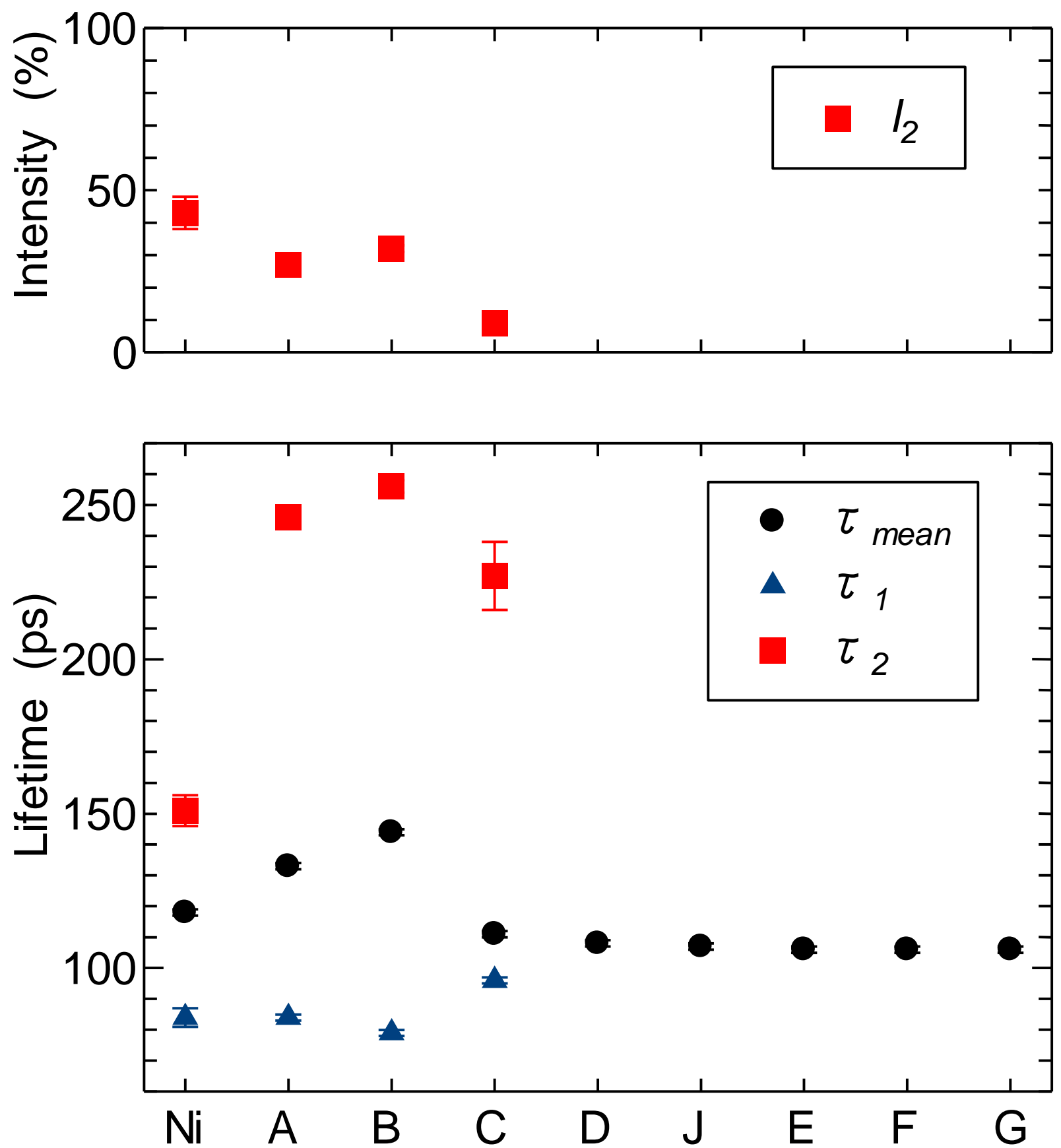

Figure 2 Positron annihilation lifetimes of electron irradiated $\mathrm{Ni}$, model alloys and commercial alloys of austenitic stainless steels at $573 \mathrm{~K}$ to a dose of $1.5 \times 10^{-2} \mathrm{dpa}$. $\tau_{\text {mean }}$ is the mean life time, and $\tau_{1}, \tau_{2}, I_{2}$ are the short lifetime, long lifetime and the intensities of the long lifetime, respectively. 

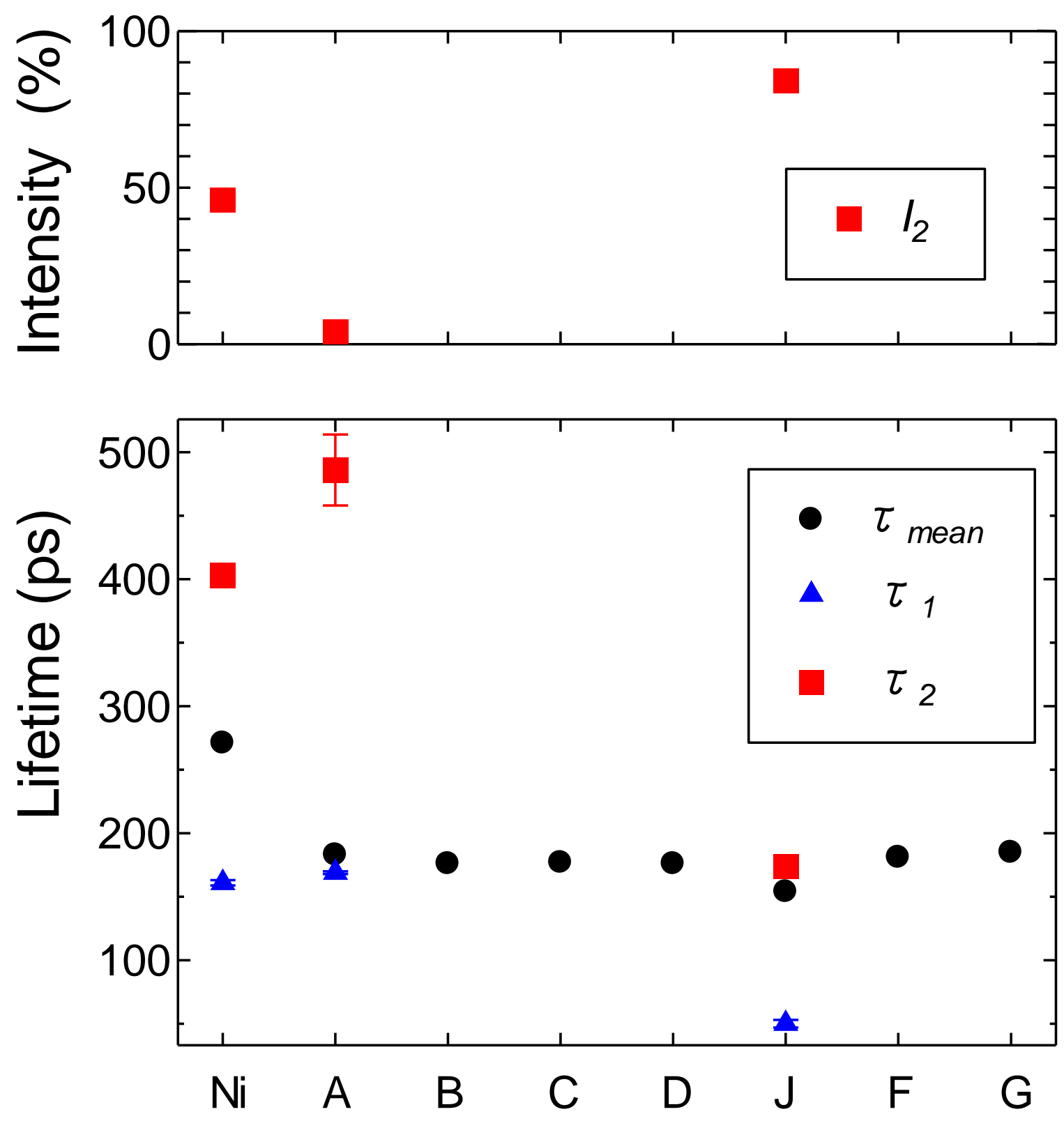

figure 3 Positron annihilation lifetimes of neutron irradiated $\mathrm{Ni}$, model alloys and austenitic stainless steels at $363 \mathrm{~K}$ to a dose of $0.2 \mathrm{dpa}$. $\tau_{\text {mean }}$ is the mean lifetime, and $\tau_{1}, \tau_{2}$ and $I_{2}$ are the short lifetime, long lifetime and the intensity of the long lifetime, respectively. 

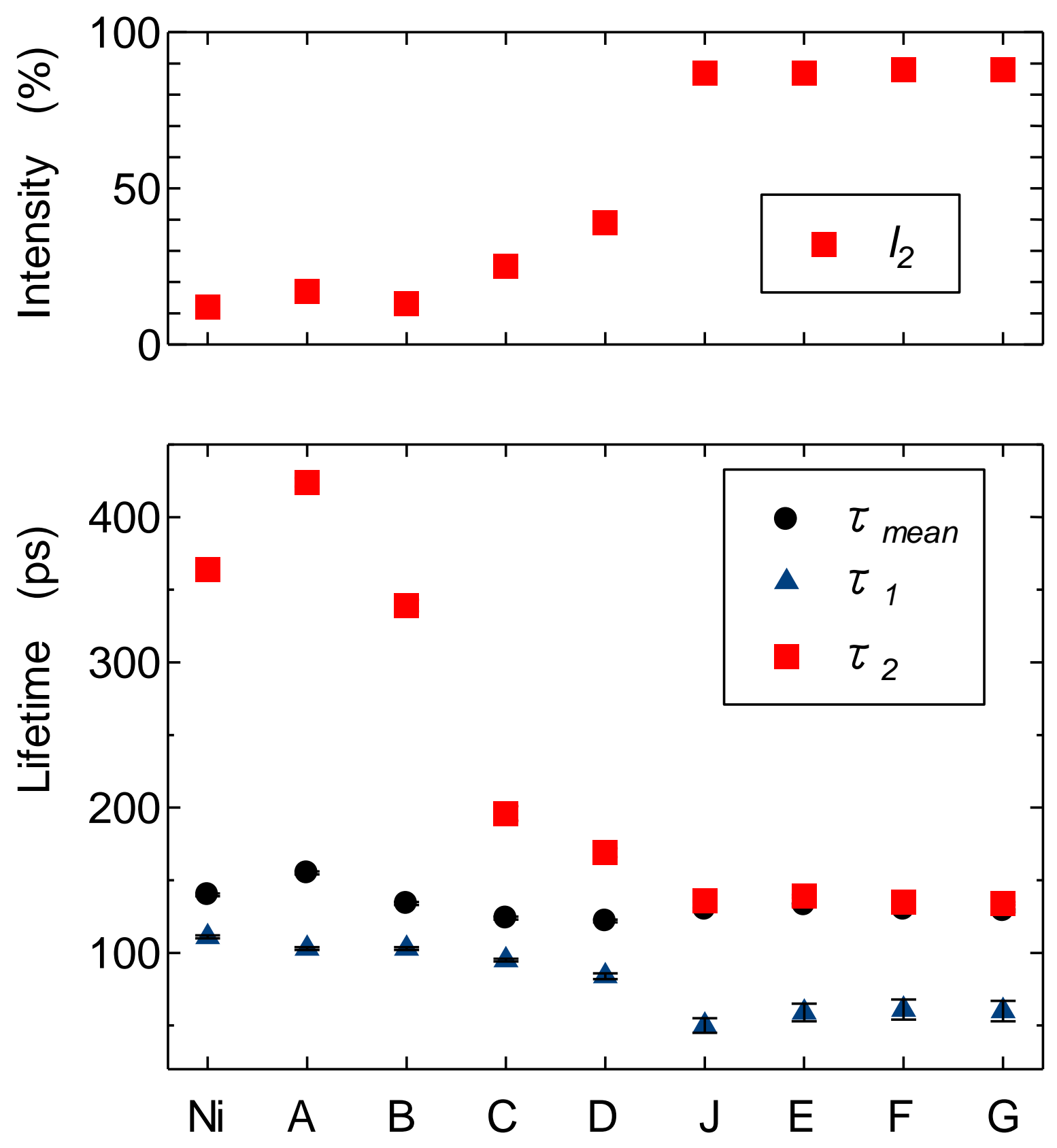

Figure 4 Positron annihilation lifetimes of neutron irradiated Ni, model alloys and austenitic stainless steels at $573 \mathrm{~K}$ to a dose of $1.6 \times 10^{-3} \mathrm{dpa} . \tau_{\text {mean }}$ is the mean lifetime, and $\tau_{1}, \tau_{2}$ and $I_{2}$ are the short lifetime, long lifetime and the intensity of the long lifetime, respectively. 

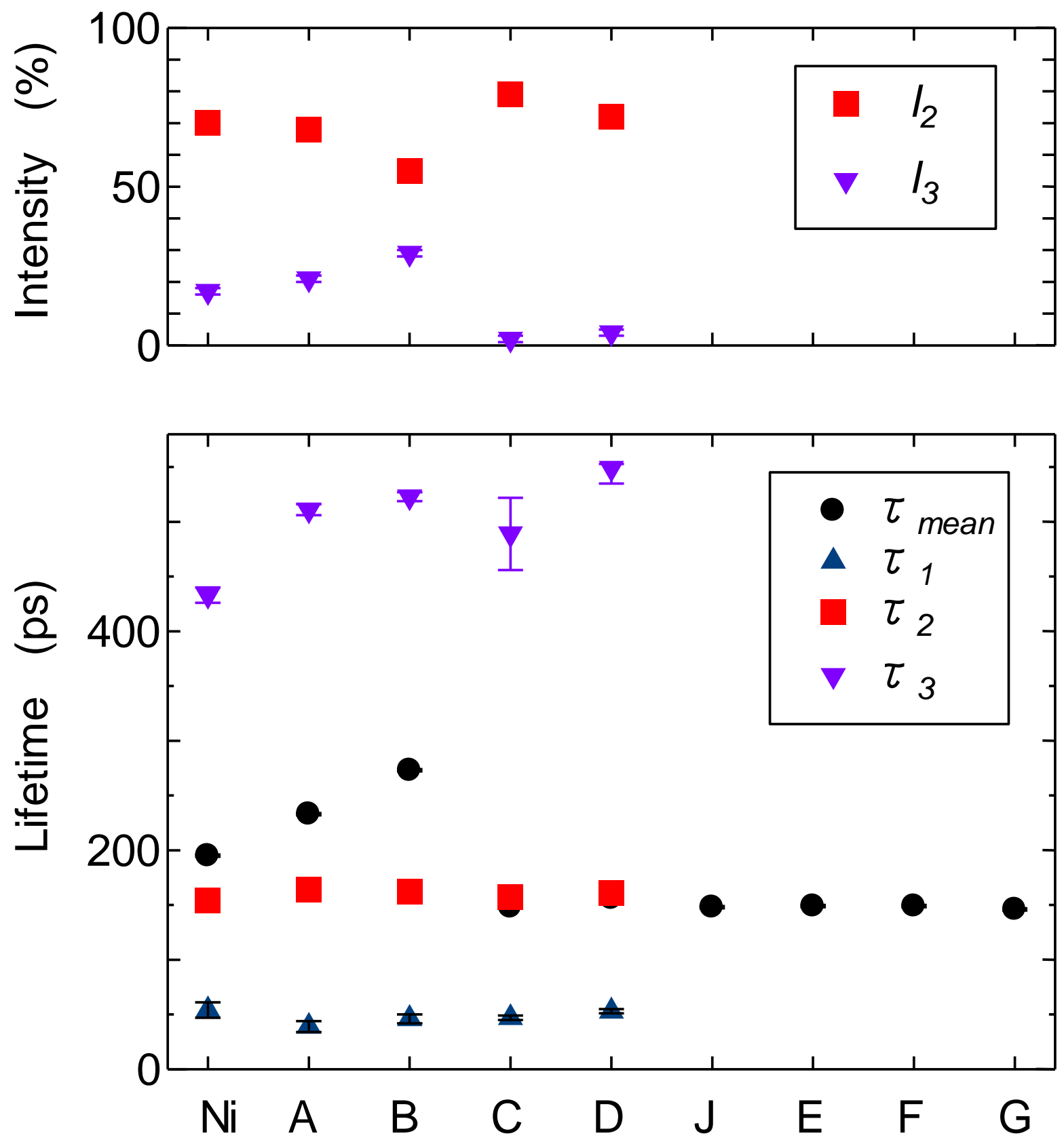

Figure 5 Positron annihilation lifetimes of neutron irradiated $\mathrm{Ni}$, model alloys and commercial alloys of austenitic stainless steels at $573 \mathrm{~K}$ to a dose of $0.2 \mathrm{dpa}$. $\tau_{\text {mean }}$ is the mean lifetime, $\tau_{1}, \tau_{2}$, $\tau_{3}, I_{2}$ and $I_{3}$ are the short lifetime, two long lifetimes and the intensities of the two long lifetimes, respectively. 